\title{
Intracranial collateral circulation and its role in neurovascular pathology
}

\author{
Harold E. Vasquez ${ }^{1,2}$, B. V. Murlimanju ${ }^{3,4}$, Adesh Shrivastava ${ }^{5}$, Yeider A. Durango-Espinosa ${ }^{1,2}$, Andrei F. Joaquim ${ }^{6}$,
} Ezequiel Garcia-Ballestas ${ }^{7,8}$, Luis Rafael Moscote-Salazar ${ }^{5}$ and Amit Agrawal ${ }^{9,10^{*}}$ (D)

\begin{abstract}
Background: Collateral circulation is a vascular network which maintains the blood flow after the partial blockage of primary vascular pathways. This acts as potential vascular supplementary system and plays important role in the cerebral ischemia.

Main body: Collateral circulation has implications in the management especially related to cerebral endovascular treatment and thrombolytic therapy. It is considered as subsidiary network of vascular channels, which is highly variable. Insufficient arterial supply is due to the hemodynamic compromise because of thromboembolism. Apart from the collaterals, there is additional existence of a group of vessels known as venous collaterals. Their function is variable and they contribute to the augmentation of venous drainage in venous ischemias. Various pharmacological interventions are used to modulate the collaterals, these can prove to be a complementary alternative to the invasive intracerebral interventions.

Conclusions: The aim of this review article is to highlight the importance of cerebral collateral circulation and to discuss the various available pharmacological alternatives available and their current relevance in the management of various neurovascular pathologies.
\end{abstract}

Keywords: Cerebral collateral circulation, Cerebral ischemia, Cerebral stroke

\section{Background}

Stroke is considered as the third cause of mortality in the world and it is producing high morbidity, by limiting the normal functioning of patients and affecting the quality of life [1]. Stroke is caused by reduction of cerebral arterial supply, which leads to deprivation of cerebral oxygen and nutrients. Within a few minutes of onset, stroke causes ischemic injury and it is considered as a medical emergency [2]. Prompt diagnosis and appropriate emergency treatment is crucial as early intervention can minimize the brain damage and subsequent potential complications [1]. However, a well-developed

\footnotetext{
*Correspondence: dramitagrawal@gmail.com

${ }^{9}$ Department of Neurosurgery, All India Institute of Medical Sciences, Saket Nagar, Bhopal, Madhya Pradesh 462020, India

${ }^{10}$ Center for Biomedical Research (CIB), Faculty of Medicine, University of

Cartagena, Cartagena, Colombia

Full list of author information is available at the end of the article
}

collateral circulation can have a protective effect on the penumbra, until the recanalization is achieved, as it can significantly minimize the area of cerebral tissues [3, 4]. The relationship between the grades of collateral circulation and the predictability of infarct evolution was a main study focus in recent years [5]. The hemodynamic effects of intracranial collateral circulation may be important to maintain perfusion in the affected regions [6]. It is a network of vascular channels that stabilize the cerebral blood flow when the main ducts fail [7]. It is a special physiological pathway that protects the tissues against acute ischemic injury during its initial phase $[2,6]$. This current review article aims to show the benefits of collateral circulation in cerebrovascular pathologies and the relevance of knowing the physiology of this system to be modulated by pharmacological strategies.

\section{Springer Open}

๑ The Author(s). 2021 Open Access This article is licensed under a Creative Commons Attribution 4.0 International License, which permits use, sharing, adaptation, distribution and reproduction in any medium or format, as long as you give appropriate credit to the original author(s) and the source, provide a link to the Creative Commons licence, and indicate if changes were made. The images or other third party material in this article are included in the article's Creative Commons licence, unless indicated otherwise in a credit line to the material. If material is not included in the article's Creative Commons licence and your intended use is not permitted by statutory regulation or exceeds the permitted use, you will need to obtain permission directly from the copyright holder. To view a copy of this licence, visit http://creativecommons.org/licenses/by/4.0/. 


\section{Main text}

\section{Collateral circulation: Overview}

Collateral vessels contribute to the arterial supply of one or more areas deprived of their primary blood supply [4]. For many years, the pathophysiology of the collateral arteries in the central nervous system has been discussed but failed to get a consensus or unified criteria and explains the existence of various classifications. At least, on the anatomical basis, two main types of cerebral collateral circulation exists, the first one being collaterals between the intracranial arteries and the extracranial arteries. The second one is collaterals of the intracranial arteries. These collateral vessels get often recruited or activated at different intervals; therefore, two types of collaterals are defined based on the activation period. The collaterals that act immediately or in minutes (early activation of collaterals) and the delayed action (delayed recruitment). Early activation depends on the speed of occlusion (for example, sudden carotid occlusion), diameter of artery, blood flow velocity, and blood flow pressure. In many cases, sudden occlusion opens up the collateral flow from the periphery to the ischemic area. However, in other cases, the presence of collaterals may not be enough to prevent ischemia and infarction. The polygon of Willis is considered as a source of collaterals of early activation, but its anatomical configuration is very variable from one individual to another [8]. As an example, this becomes inadequate through the posterior communicating artery and anterior communicating artery in approximately $25 \%$ and $36 \%$ cases, respectively [8]. This type of collateral becomes more inefficient when intracranial atherosclerosis coexists.

\section{Vascular occlusion and collateral circulation}

The role of late recruitment collaterals is usually the result of gradual arterial occlusion. The reduction of perfusion due to local hypercapnic ischemia and acidosis causes dilation of normal cerebral vessels, leading to decrease in the focal arterial pressure, which results in greater collateral flow to the ischemic area. Over time, the collateral vessels tend to widen and expand to increase the load capacity by increasing the blood volume. These changes cause the collateral vessels to become tortuous over the periods of months or years. The area of necrosis depends largely on the degree of oxygenation of the blood in poorly perfused tissues, which in turn depends on the maintenance of prolonged collateral pathway and adequate blood pressure. Clear examples of delayed or progressive recruitment are the leptomeningeal, intraparenchymal collaterals, and the external carotid artery through the branches of ophthalmic artery, the inferolateral trunk, cavernous sinus, anastomosis between branches of the middle and occipital meningeal arteries [9]. The leptomeningeal collaterals are not constant, but very variable among individuals and depend on the factors such as age and blood pressure. These are usually activated in the late occlusive vascular processes. In our experience, administering intra-arterial nimodipine, large volumes of saline solution, and pharmacological increase in the blood pressure can accelerate the process of recruitment of leptomeningeal vasculature. These represent late recruitment of collaterals, anastomosis through roots, and muscular branches of the vertebral artery, where the involvement of the anterior spinal artery has been described in some cases $[10,11]$.

\section{Types of collateral circulation}

The collateral circulation can be classified into primary (arterial segments of the circle of Willis) and secondary collateral pathways (the ophthalmic artery and leptomeningeal vessels) [7, 12-15]. Collaterals between the intracranial and extracranial arteries includes (1) branches of the external carotid artery and the cavernous segment of the internal carotid artery and ophthalmic artery, (2) dural anastomosis between distal branches of the middle and occipital meningeal artery with cerebral arteries, (3) anastomosis between extracranial segments of vertebral artery and anterior spinal artery, and (4) muscular, subcutaneous, and visceral arteries to the branches of the vertebral artery. Collaterals between the intracranial arteries includes (1) basal collaterals-communication through the vessels forming the circle of Willis (circulus arteriosus), (2) superficial collaterals-represents the pial communication through the leptomeningeal artery, and (3) intraparenchymal collaterals-small precapillary anastomosis between the branches of perforating arteries [15]. Substantial variability is an inherent characteristic of cerebral collateral circulation and a knowledge of these variations is important which are while considering interpretation of diagnostic imaging and planning therapeutic interventions [4, 15-22].

\section{Collateral circulation and ischemic cerebral vascular events}

Collateral circulation of the brain constitutes one of the most influential factors in controlling the potentially devastating effects of cerebral ischemia [4]. Liebeskind et al. [7] observed that the collateral circulation is a powerful determinant of the risk of stroke in intracranial atherosclerosis, demonstrating a protective role with severe stenosis, decreasing the metabolic need after infarction. Verma et al. [6] evaluated the pattern of distribution of early ischemic changes as a practical method to estimate the leptomeningeal collateralization in acute cerebrovascular accidents, finding that the patients with poor collaterals showed more infarcts in the initial MRI. DWI-weighted MRI sequences can be a useful marker in routine clinical evaluation [6]. Seyman et al. [14] observed that collateral circulation is an important determinant of volume of cortical infarction, affecting the clinical outcome 
in cases of established occlusion of the main anterior circulation artery.

\section{Imaging evaluation}

Evolving imaging modalities CT with perfusion protocol, MRI with perfusion protocol, xenon-enhanced CT, single-photon emission CT, positron emission tomography are useful adjunct to existing imaging modalities $[4,5]$. However, digital subtraction angiography (DSA) is considered as the gold standard for the anatomical evaluation of collateral circulation [5]. It can dynamically visualize the blood flow through the pial collaterals or other secondary collaterals. Progress in perfusion-based imaging has allowed functional evaluations of cerebral blood flow quality, which is also known as effective parenchymal perfusion.

\section{Implications in clinical practice}

It is interesting to note that collateral circulation plays an important role not only in the recovery phase of acute stroke but also in the hemorrhagic transformation of the infarct [4, 23-26]. Presence of collateral circulation is found to be protective against ischemic stroke in patients with carotid artery stenosis [4, 27, 28]. A large number of interesting strategies with the proven ability to modulate the flow of collateral circulation in cerebral ischemic events are proposed and its current status in under different clinical trials. External counter pulsation (ECP) is a method, which improves the perfusion in a non-invasive manner. It augments diastolic blood flow which is triggered by ECG and thus increases perfusion to the heart, kidney, and brain [13, 29]. An interesting strategy is the change of position of the head that after a vascular occlusion can modify the gravitational influence of pressure gradients in the cerebral circulation and in this way the leptomeningeal recruitment is increased [30].

\section{Induced hypertension and volume expansion}

The increase in systemic blood pressure seems to be one of the most practical measures to modulate collateral circulation. In small clinical studies phenylephrine, which induces systemic vasoconstriction as acting as an alpha 1 adrenergic receptor agonist, it does not improve the prognosis in the patients treated. This clarifies that the collateral circulation was not evaluated, leaving doubt about the real utility. The expansion of intravascular volume is an attractive measure; the increase in volume can be usually done by plasma expansion and hemodilution. Although it did not result in improvement of neurological outcome or mortality using dextran 40 and hydroxyethyl starch, we have to clarify that, when these trials were carried out, the therapeutic window period, which was not well defined, once patients were included over hours to days after the ischemic vascular event. On the other hand, the use of $25 \%$ intravenous albumin was not found to be superior to the conventional treatment in patients with cerebral infarction. The use of albumin for its hypervolemic effect, antioxidant, antiinflammatory, and antithrombotic properties supposed promising results. The study ALIAS 1-2, use an albumin dose of $2 \mathrm{~g} / \mathrm{kg}$, however, had to be suspended due to high mortality, increased congestive heart failure, and pulmonary edema. By this reason, use in stroke is not recommended [31, 32].

\section{Partial occlusion of aorta}

Partial occlusion of the abdominal aorta has been shown to improve cerebral through complex mechanisms [33], however, this is an invasive, technically demanding, and costly method so it is of limited use in clinical practice [34].

\section{Nitric oxide}

The induction of selective arteriolar vasodilatation in the ischemic penumbra area may be another measure to be used. The use of nitric oxide, a potent endogenous vasodilator was evaluated in basic research studies with models of cerebral infarcts. In these experimental models, nitric oxide induces selective arteriolar vasodilatation in the penumbral zone, apparently through arteries. Collaterals improved the functional prognosis and decreased the damaged brain tissue $[4,12]$. Future clinical trials in humans are required to corroborate the findings observed at the experimental level.

\section{Bypass surgery}

Extracranial and intracranial arterial bypass surgery (external carotid artery and internal carotid artery) involves the connection of superficial temporal artery with the branches of the middle cerebral artery (MCA) to avoid atherosclerotic stenosis or occlusions of the internal carotid artery or MCA. This procedure has been shown to be safe and effective; however, it should be considered for the use of general anesthesia in critically ill patients [35].

\section{Sildenafil and PDE5 inhibitors}

Phosphodiesterase inhibitors can improve the recovery time in brain injury. The initial therapeutic targets are inflammation and neuronal death, and the late objectives are synaptic dysfunction and circuit remodeling [36]. Sildenafil, an inhibitor of PDE5, has a neurorestorative effect in rats with CVA, due to its effects of neurogenesis, synaptogenesis, and angiogenesis. Its neurorestorative action is demonstrable even if the therapy starts 1 week after the stroke [37].

\section{Recombinant human erythropoietin}

The clinical utility of erythropoietin in neuroprotection is very controversial at present. However, the application 
of molecules such as $\mathrm{rHu}$-EPOb in the neurosciences as a solid theoretical basis gave promising results in preclinical studies of cerebrovascular and neurodegenerative diseases. The application of $\mathrm{rHu}-\mathrm{EPOb}$ intranasally in amounts equivalent to the pharmacological dose demonstrated its passage to the central nervous system. The effect of this on cell death, brain function, and on the safety of the acute phase of cerebral infarction, has shown its neuroprotective effect [38]. On the other hand, a high dose is tolerated in acute ischemic stroke [33].

\section{Stimulation of the sphenopalatine ganglion}

The stimulation of parasympathetic fibers, which innervate the intracranial vessels and leads into the vasodilation, is the foundation of the sphenopalatine ganglion stimulation technique. At the experimental level, this technique reduces the infarct area and has demonstrated safety in patients with cerebral infarction [39].

\section{Acetazolamide usage}

The use of carbonic anhydrase inhibitors such as acetazolamide can selectively produce selective arteriolar vasodilation. Clinically, acetazolamide is used for the cerebrovascular hemispheric reactivity test. There is little information in the literature about acetazolamide and increased collateral circulation [40].

\section{Usage of statin medications}

The usage of statins may reduce the mortality in patients with cardiovascular disease. For decades, evidence has emerged about the neuroprotective roles of statins, they have been associated with a decrease in Alzheimer's disease, probably due to their mechanisms of reduced production of $\beta$-amyloid protein (A $\beta)$, also apparently reducing the incidence of Parkinson's disease, and at experimental level some beneficial effects have been identified in the treatment of multiple sclerosis. On the other hand, the signaling function of the oxygen radical of nitric oxide can be modulated by statins. Nitric oxide locally improves blood flow by inducing a potent vasodilator response. It has been suggested that, by activating vasodilation mechanisms, neuronal death is reduced, as it has also been established that hypoperfusion is a characteristic observed in neurodegenerative diseases such as Alzheimer's disease. Studies have shown the usefulness of statins in the increase of collateral circulation in patients with cerebral infarction [39].

\section{Conclusions}

The role of collateral circulation is considered as important factor in the event of onset, evolution, management, and prognosis of ischemic cerebrovascular disease. In spite of the highly variable anatomy of collateral circulation among the individuals, the activation of the collateral circulation permit protection or at least tries to mitigate or minimize the volume of the affected cerebral tissue and associated neurological deficit. In the future, further research is highly warranted to clearly define the role of various interventions in cerebral stroke, subarachnoid hemorrhage, and other cerebral neurovascular pathology. Finalizing well-defined strategies, increased awareness among the neuro-intensivists, neurosurgeons, neurologists, and allied professionals may go a long away in reducing the mortality and morbidity. This will improve the overall neurological outcome and early re-integration into the society of the affected individuals.

\section{Abbreviations \\ ALIAS 1-2: The albumin in acute stroke study; CT: Computerized tomography; CVA: Cerebrovascular accident; DSA: Digital subtraction angiography; \\ DWI: Diffusion-weighted imagining; ECG: Electrocardiography; ECP: External counter pulsation; MCA: Middle cerebral artery; MRI: Magnetic resonance imaging; PDE5: Phosphodiesterase type 5; rHu-EPOb: Recombinant human erythropoietin}

\section{Acknowledgements}

Not applicable.

Authors' contributions

All authors have read and approved the manuscript.

\begin{tabular}{lcccccccc}
\hline & HEV & BVM & AS & YAD & AFJ & EG & LRM & AA \\
\hline Concepts & $\checkmark$ & $\checkmark$ & $\checkmark$ & $\checkmark$ & $\checkmark$ & $\checkmark$ & $\checkmark$ & $\checkmark$ \\
Design & & $\checkmark$ & $\checkmark$ & $\checkmark$ & $\checkmark$ & $\checkmark$ & $\checkmark$ & $\checkmark$ \\
$\begin{array}{l}\text { Definition of intellectual } \\
\text { content }\end{array}$ & $\checkmark$ & $\checkmark$ & $\checkmark$ & $\checkmark$ & $\checkmark$ & $\checkmark$ & $\checkmark$ & $\checkmark$ \\
Literature search & $\checkmark$ & $\checkmark$ & $\checkmark$ & $\checkmark$ & $\checkmark$ & $\checkmark$ & $\checkmark$ & $\checkmark$ \\
Data acquisition & NA & NA & NA & NA & NA & NA & NA & NA \\
Data analysis & NA & NA & NA & NA & NA & NA & NA & NA \\
Statistical analysis & NA & NA & NA & NA & NA & NA & NA & NA \\
Manuscript preparation & $\checkmark$ & $\checkmark$ & $\checkmark$ & $\checkmark$ & $\checkmark$ & $\checkmark$ & $\checkmark$ & $\checkmark$ \\
Manuscript editing & $\checkmark$ & $\checkmark$ & $\checkmark$ & $\checkmark$ & $\checkmark$ & $\checkmark$ & $\checkmark$ & $\checkmark$ \\
Manuscript review & $\checkmark$ & $\checkmark$ & $\checkmark$ & $\checkmark$ & $\checkmark$ & $\checkmark$ & $\checkmark$ & $\checkmark$
\end{tabular}

Funding

None.

Availability of data and materials

Not applicable.

Ethics approval and consent to participate Not applicable.

Consent for publication

Not applicable.

Competing interests

The author(s) declare(s) that they have no competing interests.

Author details

${ }^{1}$ Universidad del Sinu, Cartagena de Indias, Colombia. ${ }^{2}$ Consejo

Latinoamericano de Neurointensivismo (CLaNi), Cartagena de Indias, 
Colombia. ${ }^{3}$ Department of Anatomy, Kasturba Medical College, Mangalore 575004, India. ${ }^{4}$ Manipal Academy of Higher Education, Manipal, Karnataka, India. ${ }^{5}$ Neurosurgeon-Critical Care, Center for Biomedical Research (CIB), Cartagena Neurotrauma Research Group, Faculty of Medicine, University of Cartagena, Cartagena, Colombia. ${ }^{6}$ Department of Neurosurgery, University of Campinas (UNICAMP), Campinas, Sao Paulo, Brazil. ${ }^{7}$ Cartagena de Indias, Colombia. ${ }^{8}$ Department of Neurology, Neurosurgery Division, State University of Campinas, Campinas, Sao Paulo, Brazil. ${ }^{9}$ Department of Neurosurgery, All India Institute of Medical Sciences, Saket Nagar, Bhopal, Madhya Pradesh 462020, India. ${ }^{10}$ Center for Biomedical Research (CIB), Faculty of Medicine, University of Cartagena, Cartagena, Colombia.

Received: 4 May 2020 Accepted: 1 December 2020 Published online: 09 April 2021

\section{References}

1. Donkor ES. Stroke in the 21(st) century: a snapshot of the burden, epidemiology, and quality of life. Stroke Res Treat. 2018;2018:3238165.

2. Galinovic I, Kochova E, Khalil A, Villringer K, Piper SK, Fiebach JB. The ratio between cerebral blood flow and Tmax predicts the quality of collaterals in acute ischemic stroke. PLoS One. 2018;13(1):e0190811.

3. Bang OY, Goyal M, Liebeskind DS. Collateral circulation in ischemic stroke. Stroke. 2015;46(11):3302-9.

4. Liebeskind DS. Collateral circulation. Stroke. 2003:34(9):2279-84.

5. Liebeskind DS. Collaterals in acute stroke: beyond the clot. Neuroimaging Clin N Am. 2005:15(3):553-73 x

6. Verma RK, Gralla J, Klinger-Gratz PP, Schankath A, Jung S, Mordasini P, et al. Infarction distribution pattern in acute stroke may predict the extent of leptomeningeal collaterals. Plos One. 2015;10(9):e0137292.

7. Liebeskind DS, Cotsonis GA, Saver JL, Lynn MJ, Turan TN, Cloft HJ, et al. Collaterals dramatically alter stroke risk in intracranial atherosclerosis. Ann Neurol. 2011;69(6):963-74.

8. Vrselja Z, Brkic H, Mrdenovic S, Radic R, Curic G. Function of circle of Willis. J Cereb Blood Flow Metab. 2014;34(4):578-84.

9. Khatri R, Rodriguez GJ, Suri MFK, Vazquez G, Ezzeddine MA Leptomeningeal collateral response and computed tomographic perfusion mismatch in acute middle cerebral artery occlusion. J Vasc Interv Neurol. 2011;4(1):1-4.

10. Satyarthee GD. Moyamoya disease: impact of evolving different management approaches to improve overall neurologic outcome. World Neurosurg. 2017:102:684-6.

11. Satyarthee GD, Singh M. Giant unruptured middle cerebral artery aneurysm presenting with complex partial seizure: a short review. J Pediatr Neurosci. 2017;12(2):185-7.

12. Alves HC, Pacheco FT, Rocha AJ. Collateral blood vessels in acute ischemic stroke: a physiological window to predict future outcomes. Arq Neuropsiquiatr. 2016;74(8):662-70.

13. Guluma KZ, Liebeskind DS, Raman R, Rapp KS, Ernstrom KB, Alexandrov AV, et al. Feasibility and safety of using external counterpulsation to augment cerebral blood flow in acute ischemic stroke-the Counterpulsation to Upgrade Forward Flow in Stroke (CUFFS) Trial. J Stroke Cerebrovasc Dis. 2015;24(11):2596-604.

14. Seyman E, Shaim H, Shenhar-Tsarfaty S, Jonash-Kimchi T, Bornstein NM, Hallevi $\mathrm{H}$. The collateral circulation determines cortical infarct volume in anterior circulation ischemic stroke. BMC Neurol. 2016;16(1):206.

15. Ginsberg MD. The cerebral collateral circulation: relevance to pathophysiology and treatment of stroke. Neuropharmacology. 2018;134(Pt B):280-92.

16. Hartkamp MJ, van Der Grond J, van Everdingen KJ, Hillen B, Mali WP. Circle of Willis collateral flow investigated by magnetic resonance angiography. Stroke. 1999;30(12):2671-8.

17. Zhou H, Sun J, Ji X, Lin J, Tang S, Zeng J, et al. Correlation between the integrity of the circle of Willis and the severity of initial noncardiac cerebral infarction and clinical prognosis. Medicine. 2016;95(10):e2892.

18. Ryu J, Hu X, Shadden SC. A coupled lumped-parameter and distributed network model for cerebral pulse-wave hemodynamics. J Biomech Eng. 2015;137(10):101009.

19. Ginsberg MD. Expanding the concept of neuroprotection for acute ischemic stroke: the pivotal roles of reperfusion and the collateral circulation. Prog Neurobiol. 2016;145-146:46-77.
20. Sheth SA, Liebeskind DS. Imaging evaluation of collaterals in the brain: physiology and clinical translation. Curr Radiol Rep. 2014;2(1):29.

21. Cuccione E, Padovano G, Versace A, Ferrarese C, Beretta S. Cerebral collateral circulation in experimental ischemic stroke. Exp Transl Stroke Med. 2016;8(1):2.

22. Liebeskind DS, Kim D, Starkman S, Changizi K, Ohanian AG, Jahan R, et al. Collateral failure? Late mechanical thrombectomy after failed intravenous thrombolysis. J Neuroimaging. 2010;20(1):78-82.

23. Alexandrov AV, Black SE, Ehrlich LE, Caldwell CB, Norris JW. Predictors of hemorrhagic transformation occurring spontaneously and on anticoagulants in patients with acute ischemic stroke. Stroke. 1997;28(6):1198-202.

24. Lee KH, Cho SJ, Byun HS, Na DG, Choi NC, Lee SJ, et al. Triphasic perfusion computed tomography in acute middle cerebral artery stroke: a correlation with angiographic findings. Arch Neurol. 2000;57(7):990-9.

25. Lee KH, Lee SJ, Cho SJ, Na DG, Byun HS, Kim YB, et al. Usefulness of triphasic perfusion computed tomography for intravenous thrombolysis with tissue-type plasminogen activator in acute ischemic stroke. Arch Neurol. 2000;57(7):1000-8.

26. Toni D, Fiorelli M, Bastianello S, Falcou A, Sette G, Ceschin V, et al. Acute ischemic strokes improving during the first 48 hours of onset: predictability, outcome, and possible mechanisms. A comparison with early deteriorating strokes. Stroke. 1997;28(1):10-4

27. Baumgartner RW, Baumgartner I, Mattle HP, Schroth G. Transcranial colorcoded duplex sonography in the evaluation of collateral flow through the circle of Willis. AJNR Am J Neuroradiol. 1997:18(1):127-33.

28. Vernieri F, Pasqualetti P, Matteis M, Passarelli F, Troisi E, Rossini PM, et al. Effect of collateral blood flow and cerebral vasomotor reactivity on the outcome of carotid artery occlusion. Stroke. 2001;32(7):1552-8.

29. Bonetti PO, Holmes DR Jr, Lerman A, Barsness GW. Enhanced external counterpulsation for ischemic heart disease: what's behind the curtain? J Am Coll Cardiol. 2003;41(11):1918-25.

30. Schwarz S, Georgiadis D, Aschoff A, Schwab S. Effects of body position on intracranial pressure and cerebral perfusion in patients with large hemispheric stroke. Stroke. 2002;33(2):497-501.

31. Belayev L, Liu Y, Zhao W, Busto R, Ginsberg MD. Human albumin therapy of acute ischemic stroke: marked neuroprotective efficacy at moderate doses and with a broad therapeutic window. Stroke. 2001;32(2):553-60.

32. Ginsberg MD, Palesch YY, Hill MD, Martin RH, Moy CS, Barsan WG, et al. High-dose albumin treatment for acute ischaemic stroke (ALIAS) Part 2: a randomised, double-blind, phase 3, placebo-controlled trial. Lancet Neurol. 2013;12(11):1049-58.

33. Sosa I, Mengana Y, García JD, Subiros N, Cruz J, Muñoz A, et al. La eritropoyetina humana recombinante como terapia para la neuroprotección en la isquemia cerebral. Biotecnol Apl. 2008;25(1-2):25.

34. Shuaib A, Bornstein NM, Diener HC, Dillon W, Fisher M, Hammer MD, et al. Partial aortic occlusion for cerebral perfusion augmentation: safety and efficacy of NeuroFlo in Acute Ischemic Stroke trial. Stroke. 2011; 42(6):1680-90.

35. Yadollahikhales $G$, Borhani-Haghighi A, Torabi-Nami M, Edgell R, Cruz-Flores S. Flow augmentation in acute ischemic stroke. Clin Appl Thromb Hemost. 2016:22(1):42-51.

36. Knott EP, Assi M, Rao SN, Ghosh M, Pearse DD. Phosphodiesterase Inhibitors as a Therapeutic Approach to Neuroprotection and Repair. Int J Mol Sci. 2017;18(4):696. https://doi.org/10.3390/ijms18040696.

37. Zhang RL, Chopp M, Roberts C, Wei M, Wang X, Liu X, et al. Sildenafil enhances neurogenesis and oligodendrogenesis in ischemic brain of middle-aged mouse. Plos One. 2012;7(10):e48141.

38. Ehrenreich $\mathrm{H}$, Hasselblatt M, Dembowski C, Cepek L, Lewczuk P, Stiefel M, et al. Erythropoietin therapy for acute stroke is both safe and beneficial. Mol Med (Cambridge). 2002;8(8):495-505.

39. Bar-Shir A, Shemesh N, Nossin-Manor R, Cohen Y. Late stimulation of the sphenopalatine-ganglion in ischemic rats: improvement in $\mathrm{N}$-acetylaspartate levels and diffusion weighted imaging characteristics as seen by MR. J Magnet Reson imaging. 2010;31(6):1355-63.

40. Ogasawara K, Ogawa A, Yoshimoto T. Cerebrovascular reactivity to acetazolamide and outcome in patients with symptomatic internal carotid or middle cerebral artery occlusion: a xenon-133 single-photon emission computed tomography study. Stroke. 2002;33(7):1857-62.

\section{Publisher's Note}

Springer Nature remains neutral with regard to jurisdictional claims in published maps and institutional affiliations. 